\title{
Assessing the Creep Performance of Full-scale Bamboo Scrimber Columns
}

\begin{abstract}
Yan Liu, ${ }^{\mathrm{a}}$ Wenbo Jia, ${ }^{\mathrm{a}}$ Xiangyu Su, ${ }^{\mathrm{b}}$ Hongwei Ma, ${ }^{\mathrm{a}, *}$ and Zhongping Xiao ${ }^{\mathrm{c}}$
Bamboo scrimber is a kind of artificial processing material with high compressive strength, large size, natural texture, and wide application. It is made by rolling and de-fibering bamboo into a loose reticulate bundle, which is unbroken transversely, and loosely interlaced in the longitudinal direction, followed by drying, gluing, assembling, and hot pressing. In this study, to better understand the application value of bamboo scrimber in construction engineering, the performance of axially compressed solid columns that have been completed with three full-scale solid bamboo scrimber columns of $100 \mathrm{~mm}$ width, $100 \mathrm{~mm}$ height, and $2000 \mathrm{~mm}$ length were subjected to creep tests for 3 months. The specimens $\mathrm{J} 1$, J2, and $\mathrm{J} 3$ were designed to carry the long-term load of $0.2,0.4$, and 0.6 times the short-term test failure load of the same batch of specimens, respectively. The experimental study found that the bamboo scrimber columns could not bear 0.6 times of the short-term test failure load $\mathrm{Pu}_{\mathrm{u}}$, and that temperature and humidity greatly influenced creep of the specimens. Finally, a creep constitutive equation was established using a threeparameter model, and the equation matched well with the creep test data.
\end{abstract}

Keywords: Bamboo scrimber column; Creep test; Creep constitutive equation

Contact information: a: College of Civil Science and Engineering, Yangzhou University, Yangzhou, Jiangsu 225127, China; b: Science and Technology Innovation Service Center of Shanghu Innovation Zone management committee, Haian, Nantong, Jiangsu 226600, China; c: School of Architectural Engineering, Yangzhou Polytechnic Institute, Yangzhou, Jiangsu 225127, China;

*Corresponding author: njmhw001@126.com

\section{INTRODUCTION}

Bamboo scrimber is a type of engineered bamboo that owes its origins to the wood scrimber processing technology invented by Australian scientist John Douglas Coleman in 1973 (Shang et al. 1998). It consists of a square or rectangle plate with high strength, large size, and natural bamboo texture made from long, cross-linked, loose reticular fiber bundles - maintaining the original arrangement of fibers - dried at low temperatures to less than $12 \%$ moisture content. These are then made by the parallel lay-up, glued, and hot pressed. Bamboo scrimber has the preferred characteristics of the high utilization rate of bamboo, good physical and mechanical properties, appealing aesthetics, and cost-effective commercial as well as reliable construction material (Li et al. 2001).

As a polymer composite material, bamboo scrimber has rheological properties, meaning its structure will undergo creep deformation under long-term loads. To avoid excessive creep and to understand the compressive creep performances of bamboo scrimber columns, it is necessary to subject them to axial compression creep tests. Since there is little published research on the creep performance of bamboo scrimber columns, this study has referred to related research methods used for assessing wood creep.

In the 1960s, Armstrong (Armstrong et al. 1960, 1961) proposed that changing the 
moisture content would influence the creep properties of wood. Later, Bhatnagar (1964) pointed out that the relationship between creep strain and stress in the wood was a linear function when the stress in the specimen was less than or equal to a certain value, and when it exceeded that value, the relationship was non-linear. Schniewind (1967) found that the periodic variations of relative humidity and temperature in the environment led to significant reductions in the average time of small beams of Douglas fir to failure at a given load level. In the 1970s, the concept of mechanical adsorption creep was proposed (Grossman 1976). Consequently, the relationship between wood deformation and the time at which the water content, temperature, or circulation conditions under stress are changed was suggested for the first time. Leicester (1971) introduced a creep interpretation model for mechanical adsorption characteristics. Bazant (1985) had proposed that wood is a linear viscoelastic material under the stress limit and constant temperature as well as humidity conditions.

Chinese scientists also have conducted much research on wood creep. In 1989, the compression rheological properties of oak wood cross-grain and white poplar-planed flakes were reported (Shi and Wang 1989; Wang 1989). At the same time, Liu and Li (1989, 1996a) presented a viscoelastic model for wood creep, later reporting on the creep characteristics of several major tree species. One notable study proposed that resin $\mathrm{pH}$ affects the creep properties of particleboard (Wang 1990). Other reports describe the creep characteristics of Phyllostachys pubescens under various stress levels, and temperature and moisture content (Xu et al. 2007), and a discussion of rheology applications to research on wood composite materials, namely particleboard, plywood, medium-density fiberboard, veneer laminated wood, paper wood composite board, and wood-plastic composite material (Hu et al. 2008). Ma et al. (2008) reviewed the rheological properties of wood and composite materials, and prospected for further research on wood rheology in the future, including the accelerated characterization of wood long-term rheological properties based on timetemperature-stress equivalence principle and the application of the genetic algorithm in wood rheological research.

Creep of a full-scale glued bamboo bridge strengthened by carbon fiber-reinforced plastics (CFRP) has been observed for 3.5 years by Xiao et al. (2013). The ensuing analysis revealed the rule of creep deformation during the period. After the uniform load was removed, a subsequent short-term damage test showed that CFRP not only improved the mechanical performance of bamboo beams but also met the requirements of strength and durability in practical engineering. Using a self-developed creep device, Wang (2007) and Zhou (2009) carried out tensile and compression creep tests of LVL (laminated veneer lumber) under various load levels, analyzed the influencing factors of creep constitutive model of LVL, and established a relationship between creep strain and time. A user material subroutine (UMAT) has been developed for creep calculation using commercial software ABAQUS, and has been used to numerically simulate the effect of long-term deformation and creep on the stability of wood arches and reticulated shells. Liu et al. (2016) selected three sets of full-scale LVL columns made from poplar LVL for a 1-year creep test. That study showed that creep deformation mainly includes elastic, viscous, and viscoelastic deformations, with changes in temperature and humidity having a considerable influence on creep deformation. A constitutive creep equation was established, and the simulated value coincided well with the test data. A tensile and compressive creep test of full-scale model bamboo scrimber provided information of these properties under ideal conditions (Wu 2015), as did another a creep test conducted on bamboo scrimber beams (Li et al. 2015). 
Thus far, the creep tests of bamboo scrimber columns, both in China and abroad, are less and limited to the scale model under ideal conditions. The creep law established by the scale model is quite different from that of the full-scale model (Liu et al. 2016). In this paper, the long-term compression of full-scale bamboo scrimber columns was studied in detail to reveal the creep behavior rules of such columns and to explore potential applications of full-scale bamboo scrimber columns for building structures.

\section{EXPERIMENTAL}

\section{Methods and Materials}

The specimens were produced by Jiangxi Chun Hong Bamboo Technology Co., Ltd. (Jiangxi Province, China). The size of bamboo scrimber columns used was $100 \mathrm{~mm} \times 100$ $\mathrm{mm} \times 2000 \mathrm{~mm}$ (width $\times$ height $\times$ length). The physical and mechanical properties of the same batch of bamboo scrimber specimens before the long-time loading test were determined. According to these results, bamboo scrimber had an air-dried density of 1.204 $\mathrm{g} / \mathrm{cm}^{3}$, average moisture content of $6.6 \%$, compressive strength along the grain of 57.35 $\mathrm{MPa}$, standard compressive strength along the grain of $55.47 \mathrm{MPa}$, elastic modulus along the grain of $1180 \mathrm{MPa}$, and a Poisson ratio of 0.384. From a previous (Liu et al. 2020) axial compression test of the same batch of bamboo scrimber columns, the failure load of the specimens under axial compression was $340 \mathrm{kN}$. In this study, the creep load of specimens $\mathrm{J} 1, \mathrm{~J} 2$, and $\mathrm{J} 3$ was set at $0.2,0.4$, and 0.6 times more of the failure load value, respectively, as shown in Table 1 . With the 0.6 times stress ratio, two specimens were loaded twice.

Table 1. Compression Creep Load of Bamboo Scrimber Columns

\begin{tabular}{|c|c|c|c|}
\hline Specimens & Stress Ratio & Creep Stress (MPa) & Creep Load (KN) \\
\hline J1 & 0.2 & 6.8 & 68 \\
\hline J2 & 0.4 & 13.5 & 135 \\
\hline J3 & 0.6 & 20.5 & 205 \\
\hline
\end{tabular}

\section{Design of Loading Device}

To study the creep performance of the specimens under long-term loading, a new type of self-balancing device for creep test was designed based on the research of Liu et al. (2016). A schematic of the loading device is shown in Fig. 1. The jack at the bottom loads the device, and the applied load passed through the foot steel plate, spring, middle steel plate, the pressure sensor, and top steel plate, and finally it was borne by the specimen. After the value in pressure sensor reached specified load, the foot steel plate's position was fixed with a nut. In this loading process, the compressive deformation was produced in the spring. When the pressure sensor reads down and pressure in the specimen decreased due to axial and lateral deformations under the long-time load, then the spring elongated, and replenished the pressure. The function of the spring was to maintain a stable load.

\section{Experimental Scheme and Measuring Point Arrangement}

The experiments were performed according to China's current code for the design of timber structures GB 50005-2003 (2005) and ASTM D198 (2015), in the Mechanics Laboratory of Yangzhou University (Yangzhou, China). The creep test started on June 27, 2017, and ended 3 months later, on September 27, 2017. 


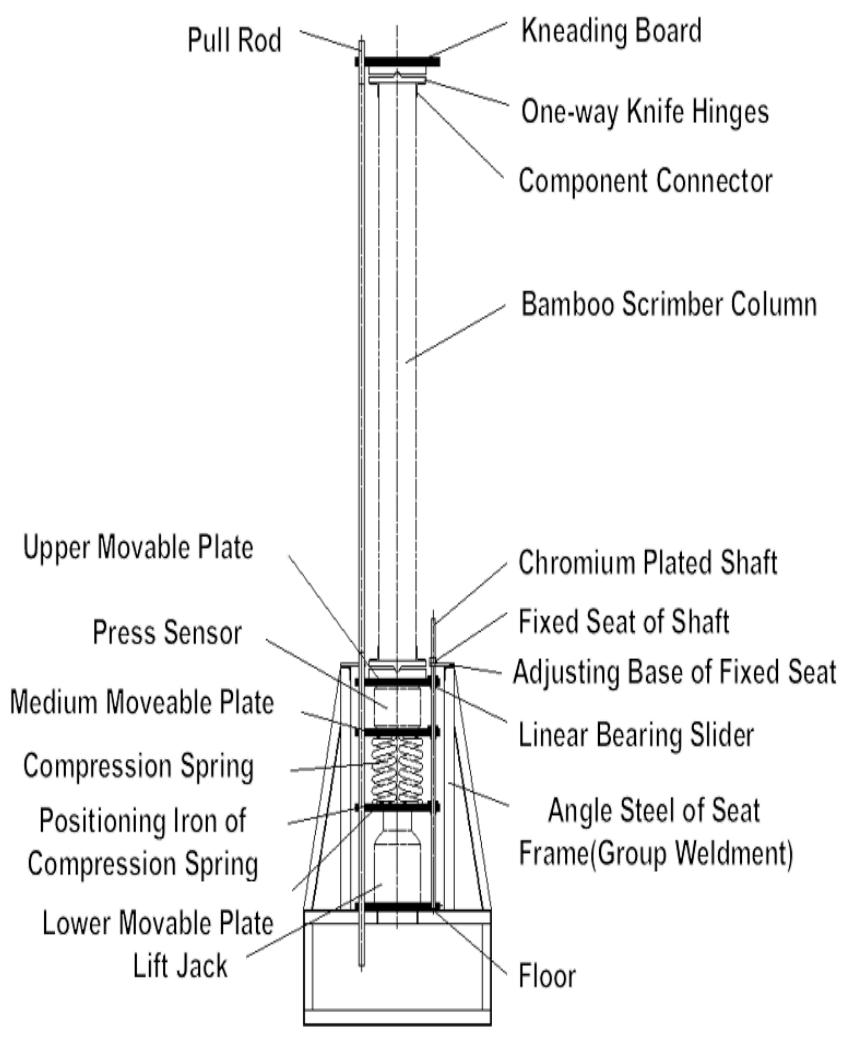

(a)

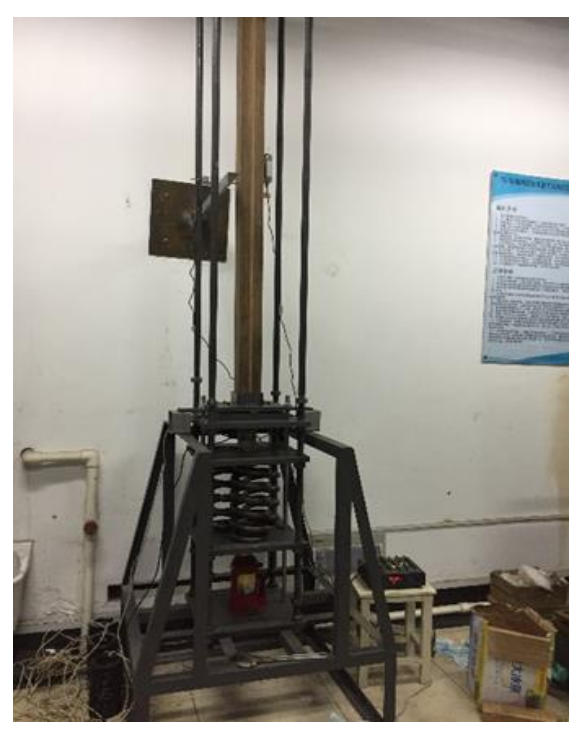

(b)

Fig. 1. Test setup: (a) Device design drawing; and (b) test device

The main purpose of this paper was to study the effect of long-term load on the creep behavior of bamboo scrimber columns. Because this test time was in the summer, all doors and windows were kept closed and curtains were drawn to avoid direct sunlight. This was done to simulate a relatively constant temperature and relative humidity environment. Meanwhile, the indoor temperature and relative humidity were measured and recorded on a daily basis.

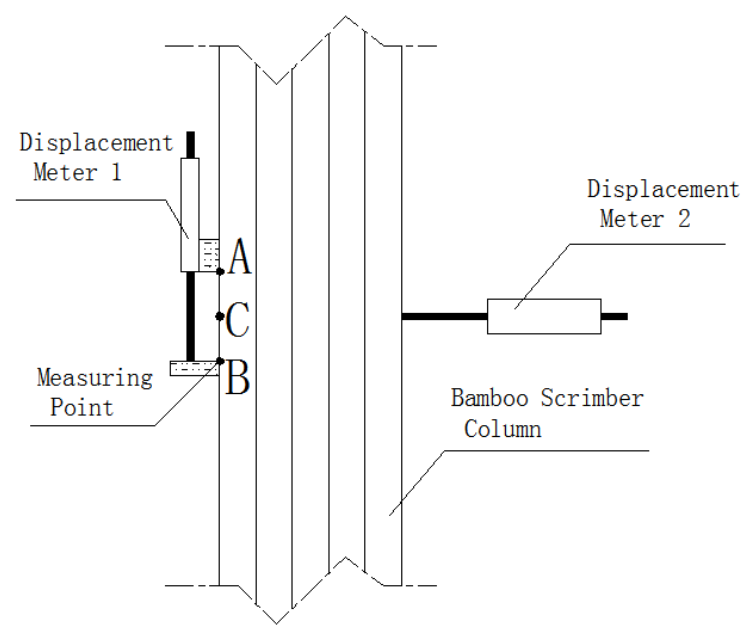

Fig. 2. Arrangement of measure point layout 
The two ends of each specimen were hinged with one-way knife hinges. Before loading, a geometric alignment of the specimen, lifting jack, spring, and pressure sensor was made to prevent initial peculiarities and to ensure that all layers of the steel plate were horizontal and could slide up and down freely.

Wire displacement meters were placed in the middle of a specimen, and the axial creep and lateral deflection values of each specimen were recorded manually. Specifically, during the first week of loading, test data were recorded every $3 \mathrm{~h}$, and then four times a day. The measure point layout and the creep test were executed as shown in Fig. 2.

\section{RESULTS AND DISCUSSION}

\section{Temperature and Humidity Record}

The temperature and relative humidity changes during the test are shown in Fig. 3. From the figure it can be found that the ambient temperature of the test room was approximately 22 to $26^{\circ} \mathrm{C}$. The temperature increased somewhat during the period of the $40^{\text {th }}$ to $60^{\text {th }}$ day owing to the external high temperature in the environment. The relative humidity decreased a little in the first 40 days, and then it remained at $60 \%$ to $66 \%$ in the $20^{\text {th }}$ to $40^{\text {th }}$ days. The relative humidity cycle was $63 \%$ to $73 \%$ during the $40^{\text {th }}$ to $90^{\text {th }}$ days of the experiment because of the heat and humidity of the rainy season in Yangzhou.

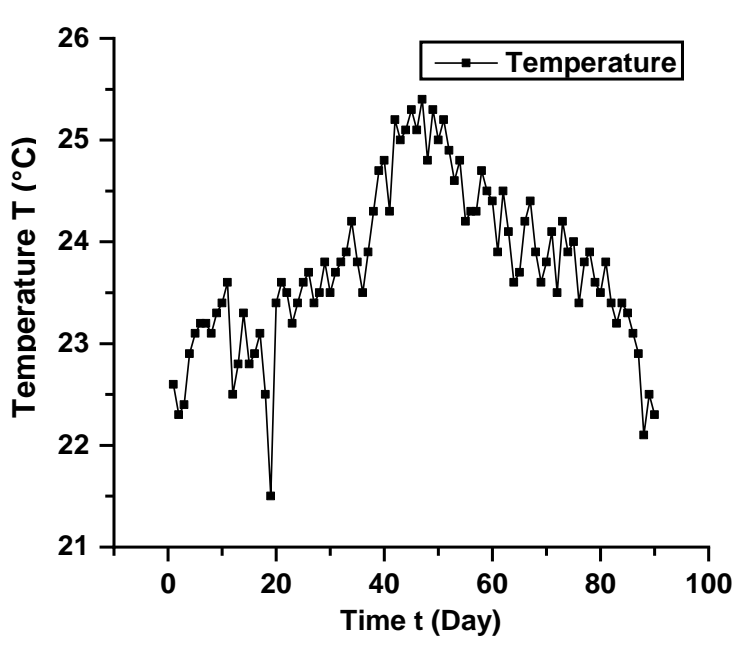

(a)

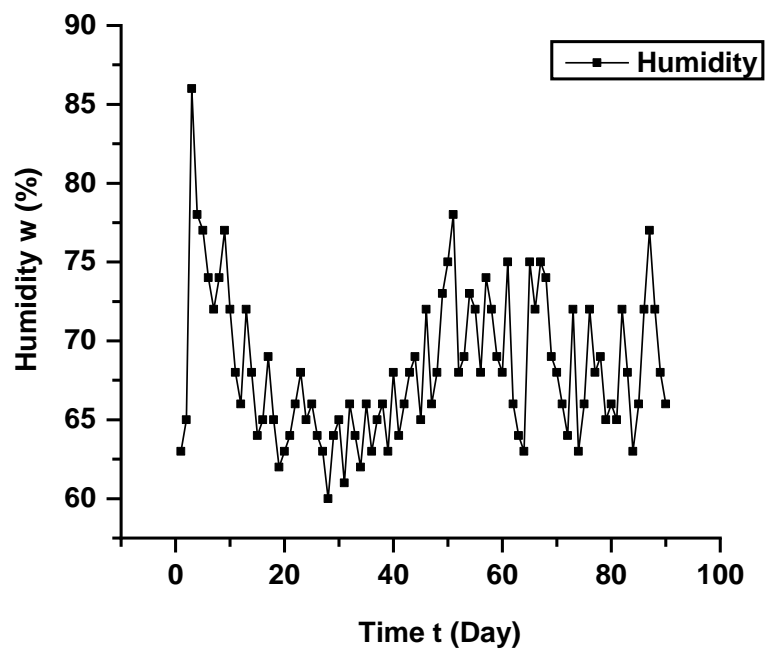

(b)

Fig. 3. Change of temperature and humidity: (a) Temperature time curve in test environment; and (b) Humidity time curve in test environment

\section{Experimental Phenomena}

Three sets of experimental devices were used to carry out long-term load tests with three stress ratios at the same time, and only one specimen was used for creep tests with each stress ratio. In the axial compression creep test of 0.6 times stress ratio, the specimen failed on the third day after loading. As a result, to eliminate the accidental error of test specimen and make the test result more reliable, the second 0.6 times stress ratio experiment was conducted with a specimen of the same size, which also was destroyed 
suddenly on the $8^{\text {th }}$ day of loading (Fig. 4). These results indicated that the full-scale solid bamboo scrimber column would not bear large long-term loads because of the various finger connection positions, and the quality of plate surface gluing. The maximum longterm load of full-scale solid bamboo scrimber column was suggested to be less than 0.6 times the ultimate load.

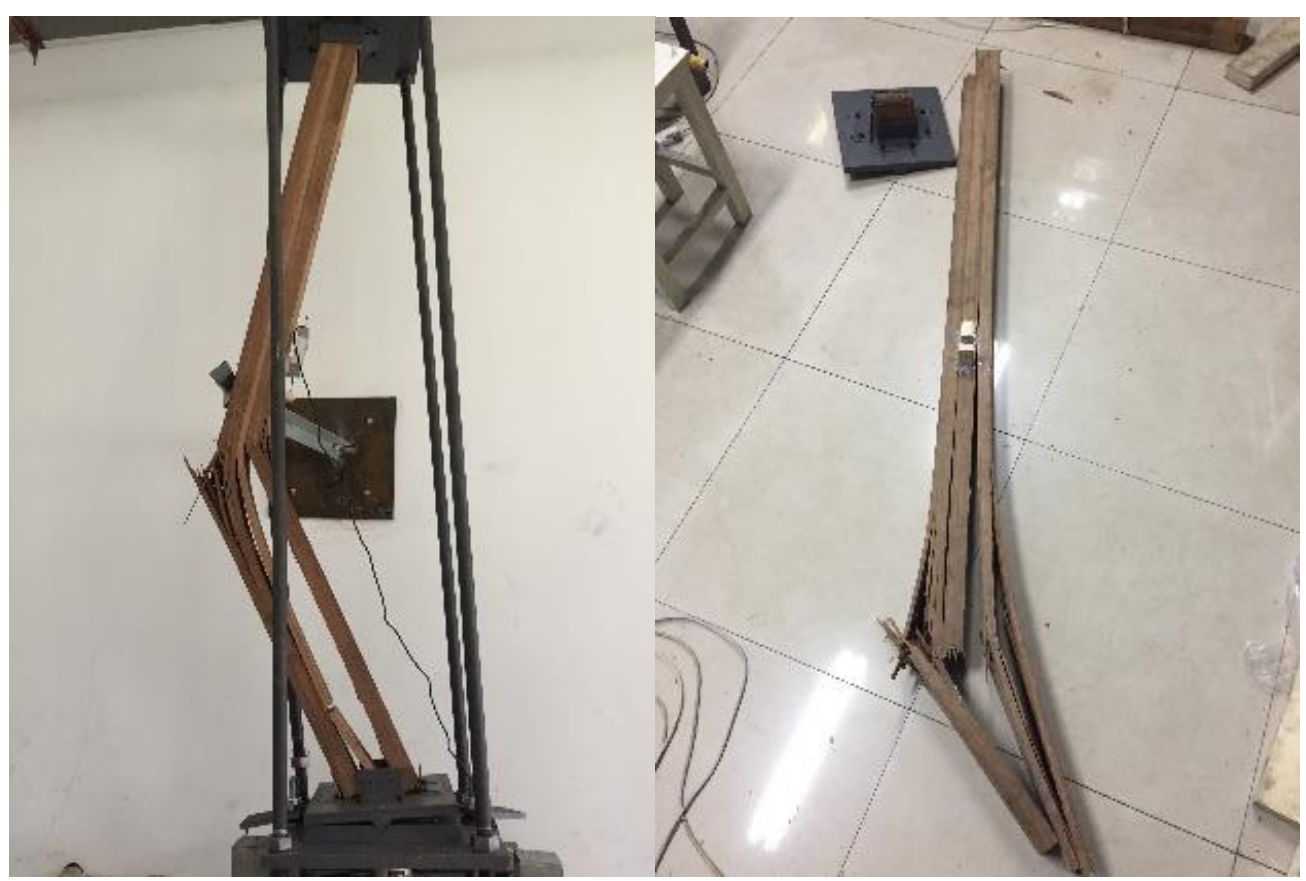

(a) (b)

Fig. 4. Failure modes of the bamboo scrimber columns: (a) the 0.6 times stress ratio experiment; and (b) the second 0.6 times stress ratio experiment of specimens

The long-term loading tests from the other two stress ratios were carried out until the end of the tests, and only one specimen was used for creep tests with each 0.2 times stress ratio and 0.4 times stress ratio.

\section{Creep Strain}

Figure 5 shows the creep deformation of a full-scale solid bamboo scrimber column under the stress levels of 0.2 times and 0.4 times. The two specimens did not enter the third stage of creep (Liu et al. 2016), namely, the non-convergence creep stage. The creep of the bamboo scrimber column can be divided into two stages: the first is the transition creep stage, in which the strain imposed increases with time, but the rate of increase gradually slows; the second is the constant creep stage, named such because the strain remained generally stable. Both specimens entered the steady-state of creep around day 50, after which it was mostly stable. From Fig. 5, it can be seen that the creep strain of the specimens under 0.2 and 0.4 times stress level had similar changes with the increase of time. Comparing the two creep curves, evidently, the creep deformation of the specimen increased correspondingly with its increased load, which is consistent with the findings of Itani et al. (1986). 


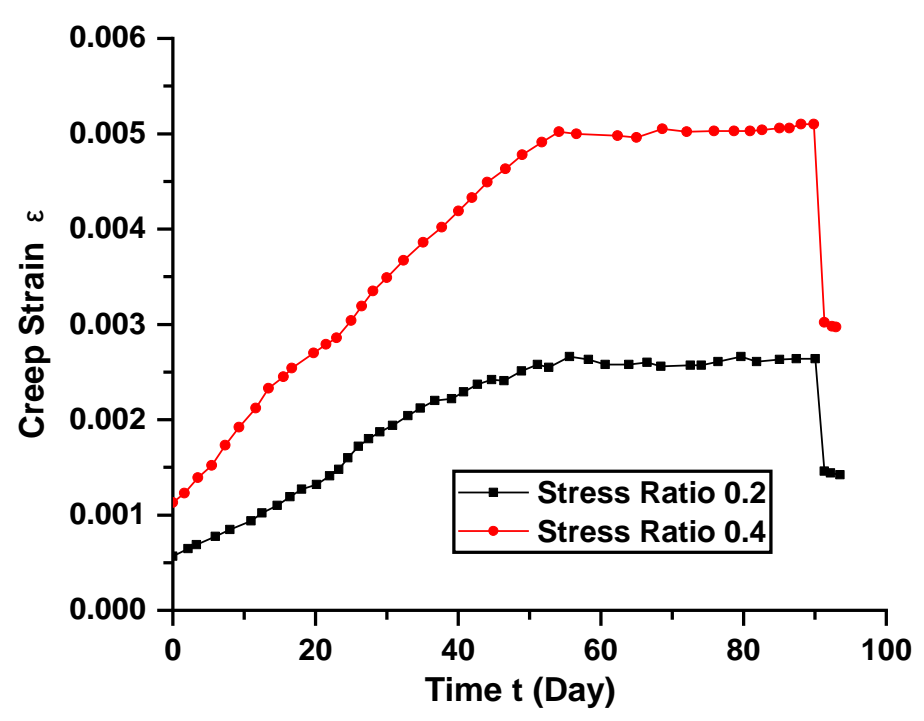

Fig. 5. Creep strain-time curve of bamboo scrimber columns

The creep properties of the bamboo scrimber column under the 0.4 times stress level were further analyzed. Figure 6 depicts the strain change during unloading, and the solid-line curve after unloading expresses the creep recovery, which happened in a relatively short time. A sudden drop then appears in the strain curve, representing the elastic recovery deformation $\left(\varepsilon_{\mathrm{e}}\right)$ of the specimen after unloading. There was also evidence of viscoelastic deformation $\left(\varepsilon_{\mathrm{de}}\right)$ and viscous deformation $\left(\varepsilon_{\mathrm{v}}\right)$ in the residual deformation of the specimen. According to work by Sheng (2015), with more time elapsed since unloading, $\varepsilon$ de can be gradually restored, whereas $\varepsilon \mathrm{V}$ is permanent deformation. It is reasonable to speculate on the creep strain curve that went unrecorded during unloading (see the dashed line in Fig. 6).

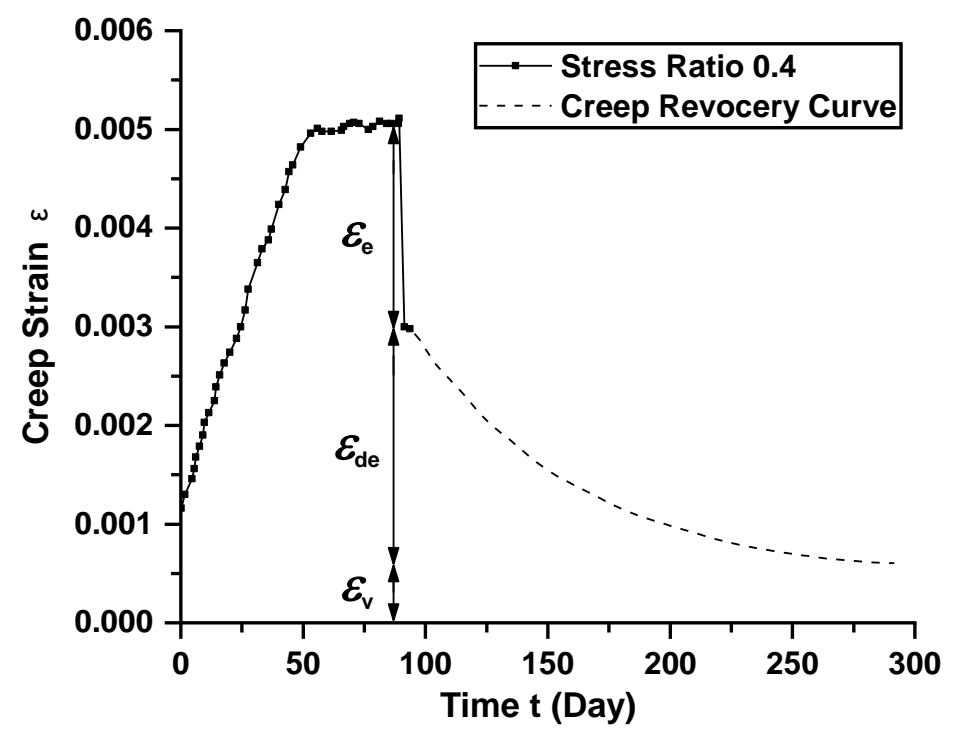

Fig. 6. Unloading creep strain-time curve with the stress ratio of $0.4 x$ 
To study the relationship between creep strain and temperature and relative humidity of bamboo scrimber column, the creep strain data of specimen with a stress ratio of 0.4 in 60 to 80 days were analyzed. Figure 7 a shows the creep strain-temperature relationship when the relative humidity was approximately $68 \%$, and Fig. $7 \mathrm{~b}$ shows the creep strain-humidity relationship when the temperature was approximately $24{ }^{\circ} \mathrm{C}$. From Figs. 6 and 7, it can be found that the fluctuation of temperature and relative humidity had a certain influence on creep strain. The creep strain increases with the increase of temperature and relative humidity, which is consistent with the research in reference (Liu et al. 2016).

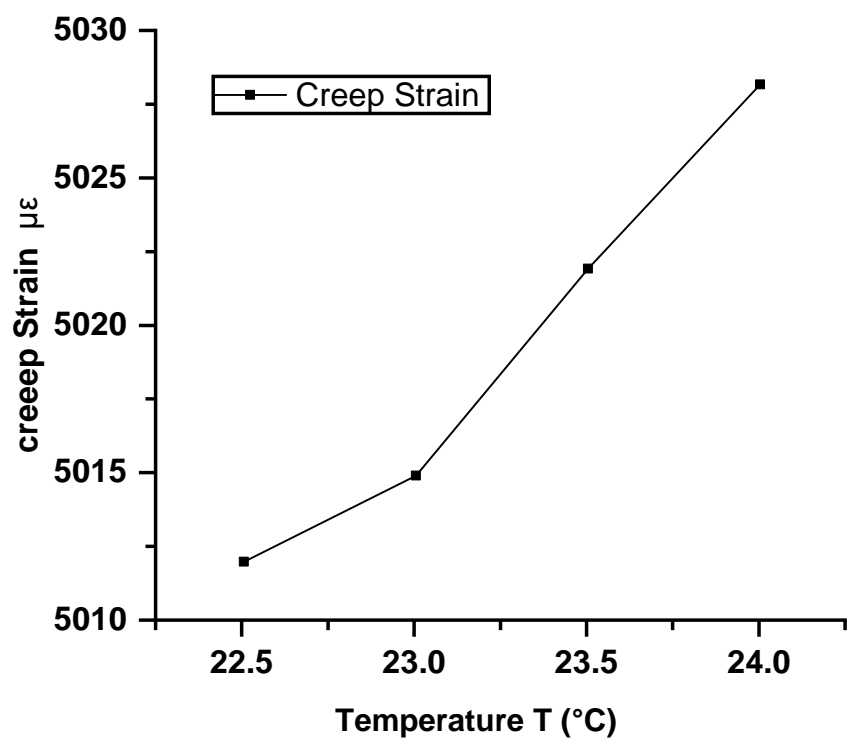

(a)

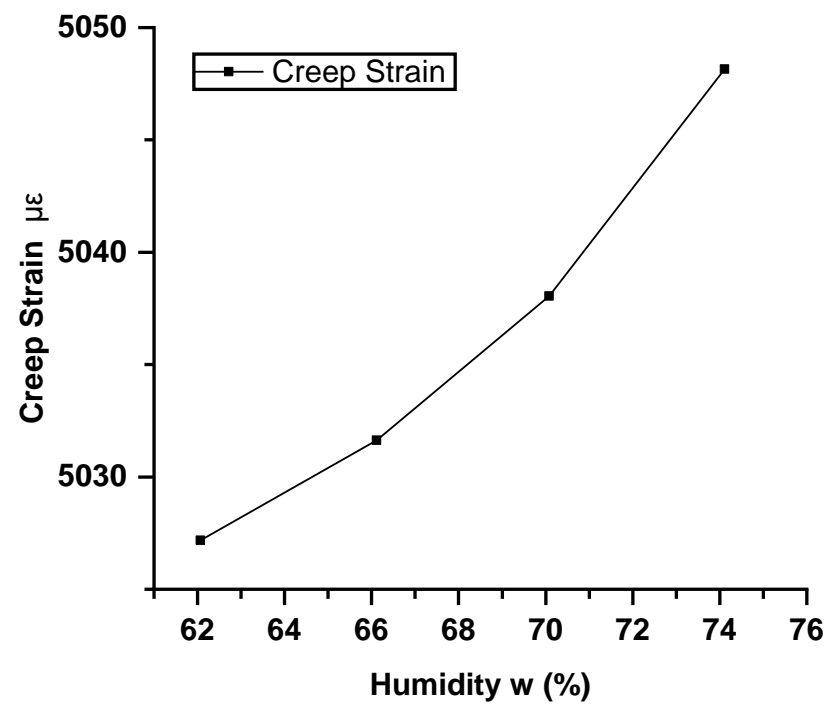

(b)

Fig. 7. Bamboo scrimber column with the stress ratio of $0.4 \times$ : (a) Creep strain-temperature relationship and (b) creep strain-humidity relationship 


\section{Lateral Deflection}

Figure 8 shows the time versus lateral deflection curve of the bamboo scrimber column under the 0.2 and 0.4 times stress level. There were similarities in the creep deflection of the two groups of specimens, and the lateral deflection of both columns would enter the stable stage at $c a .20$ to 30 days. In the middle and later stage of the experiment, the indoor relative humidity changed more than before, and the lateral deflection of bamboo scrimber column also fluctuated due to the wet and hot rainy environment. In addition, the influence of temperature and relative humidity cycle on lateral deflection of bamboo scrimber columns is similar as that on creep strain, which is not going into much detail here. From Fig. 9, it can be found that the lateral deflection of bamboo scrimber columns was small and is mainly an elastic type of deformation.

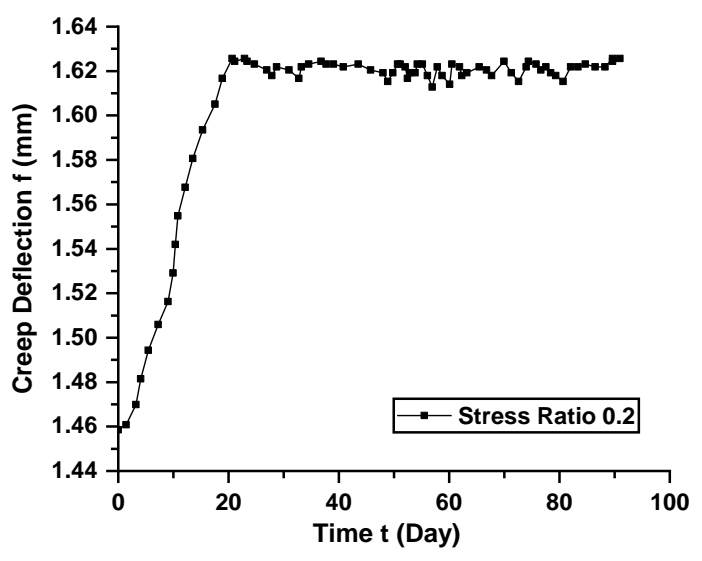

(a)

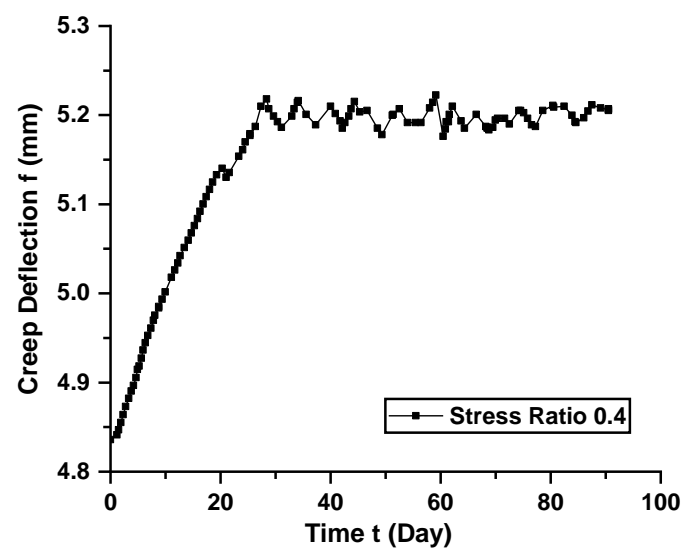

(b)

Fig. 8. Creep deflection-time curve: (a) 0.2 times stress ratio curve of bamboo scrimber columns; (b) 0.4 times stress ratio curve of bamboo scrimber columns

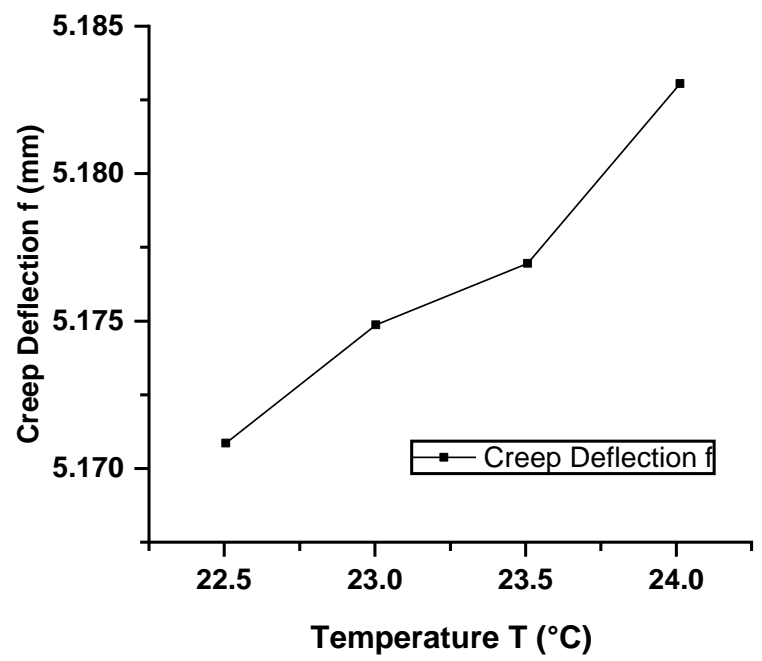

(a) 


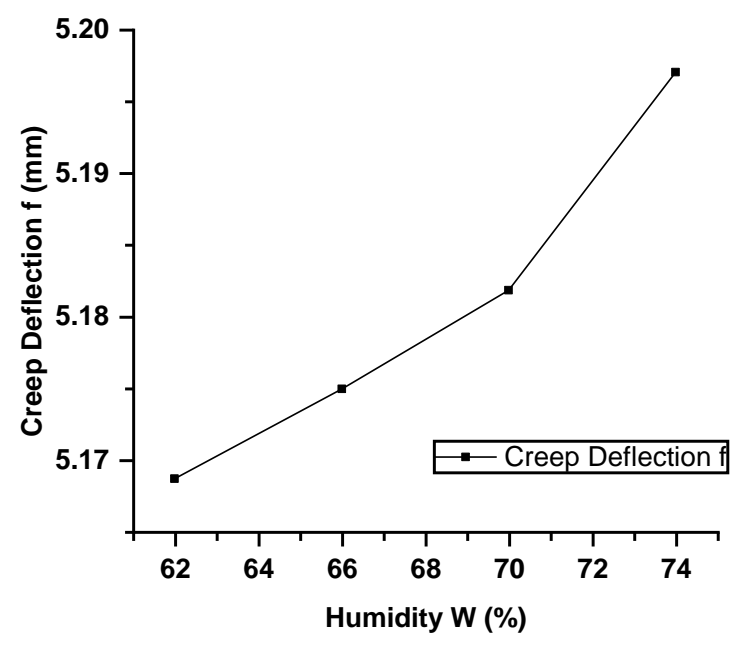

(b)

Fig. 9. Influence of temperature and humidity on creep strain: (a) creep deflection-temperature relationship of bamboo scrimber column with the stress ratio of $0.2 x$; (b) creep deflectionhumidity relationship of bamboo scrimber column with the stress ratio of $0.4 \mathrm{x}$

In summary, it can be found that both temperature and relative humidity affect the creep strain and lateral deflection of bamboo scrimber columns. Therefore, the influence factors of temperature and humidity should be considered when studying the creep mechanism of bamboo scrimber columns.

\section{Theoretical Analysis and Discussion}

The creep of the bamboo scrimber column is a long-term process, and the two creep stages mentioned above are common in engineering. Therefore, the two creep stages of the bamboo scrimber column are mainly discussed and analyzed. Sheng (2015) had fitted a constitutive equation of laminated veneer lumber specimens made from poplar according to a three-parameter model, the Burger model, and a classical creep model. That comparative study showed that the three-parameter constitutive equation could be applied to improve engineering practices. Here, the creep constitutive model of the bamboo scrimber column based on this three-parameter solid model was established using the least square regression method and considering the influence of temperature and relative humidity. The three-parameter model was made up of a Kelvin model and a spring in series (Fig. 10). The creep expression of the model is calculated as follows,

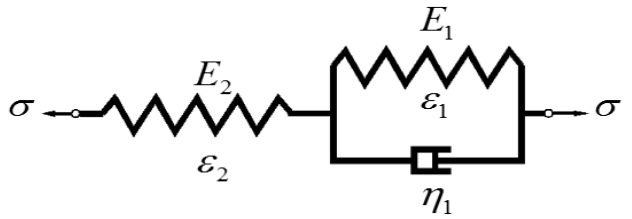

Fig. 10. Three- parameter solid model with creep for bamboo scrimber column

$$
\varepsilon(t)=\frac{\sigma_{0}}{E_{2}}+\frac{\sigma_{0}}{E_{1}}\left(1-e^{\frac{-t}{\tau_{1}}}\right)
$$


where $\sigma_{0}$ is a constant compressive stress, and $\tau_{1}=\eta_{1} / E_{1}, E_{1}, E_{2}$, and $\eta_{1}$ are the elastic coefficients and viscosity coefficient incorporating environmental relative humidity and temperature. forms,

To predict the creep behavior of this model, Eq. 1 was organized into the following

$$
\varepsilon=A+B e^{C t}
$$

where $t$ is creep time (days), while A, B, and C are constants related to materials used as parameters for fitting the equations, where:

$$
A=\frac{\sigma_{0}}{E_{1}}+\frac{\sigma_{0}}{E_{2}}, B=-\frac{\sigma_{0}}{E_{1}}, C=-\frac{E_{1}}{\eta_{1}}
$$

Fridley et al. (1992) considered the change process of humidity and temperature when determining the elastic coefficient and viscosity coefficient in Burger model, and obtained a transformation equation group. In this paper, the Burger model transformation equations of Fridley et al. (1992) are used for reference. The humidity correlation coefficient $w$ and the temperature coefficient correlation coefficient $\theta$ are introduced into the three parameter model,

$$
\begin{aligned}
& E_{1}(w, \theta)=E_{1 s}\left(1+D_{1} w+D_{2} w^{2}+D_{3} \theta+D_{4} \theta^{2}\right) \\
& E_{2}(w, \theta)=E_{2 s}\left(1+D_{5} w+D_{6} w^{2}+D_{7} \theta+D_{8} \theta^{2}\right) \\
& \eta_{1}(w, \theta)=\eta_{1 s}\left(1+D_{9} w+D_{10} w^{2}+D_{11} \theta+D_{12} \theta^{2}\right)
\end{aligned}
$$

where $E_{1 \mathrm{~s}}, E_{2 \mathrm{~s}}$, and $\eta_{1 \mathrm{~s}}$ are the elastic and viscous coefficients in the three parameter model, and they are also the elastic and viscous coefficients of the reconstituted bamboo column at the beginning of the test. $D_{1}$ through $D_{12}$ are the model constants, $w$ are the relative humidity correlation coefficients, $\theta$ are the temperature correlation coefficients, and $E_{1}, E_{2}$, and $\eta_{1}$ are the elastic coefficients and viscosity coefficients of the historical process considering the humidity and temperature.

Moisture content and temperature are known to affect the mechanical properties of wood. For the four-element model defined previously, the values of $E_{1}, E_{2}$, and $\eta_{1}$ must be adjusted for their hygrothermal state. To accomplish this, two non-dimensional factors are introduced as follows,

$$
\begin{aligned}
& w=\frac{M-M_{0}}{M_{0}} \\
& \theta=\frac{T-T_{0}}{T_{0}}
\end{aligned}
$$

where $M$ denotes humidity reading (\%), $M_{0}$ represents reference humidity reading $(\%), T$ is temperature reading $\left({ }^{\circ} \mathrm{C}\right)$, and $T_{0}$ denoted reference temperature reading $\left({ }^{\circ} \mathrm{C}\right)$.

The initial creep $\varepsilon_{0}$ of bamboo scrimber column is given as,

$$
\varepsilon_{0}=\frac{P_{i}}{A E}
$$

where $\varepsilon_{0}$ is initial elastic strain $(\mathrm{mm}), P_{i}$ is the determined creep load $(\mathrm{KN}), A$ is the section size of a specimen (mm), and $E$ is the elastic modulus (GPa). As the size of the specimen, $P_{\mathrm{i}}$ and $E$ have been known, substituting $P(340 \mathrm{kN})$ and $E(11810 \mathrm{MPa})$ into Eq. 7 yields the initial strain upon the specimen (Table 2). 
Table 2. Initial Strain of Bamboo Scrimber Columns

\begin{tabular}{|c|c|}
\hline Stress Ratio & Initial Strain $\varepsilon_{0}$ \\
\hline 0.2 & 0.000584 \\
\hline 0.4 & 0.001160 \\
\hline
\end{tabular}

By bringing the initial strain value into Eq. 2, ORIGIN (a kind of scientific drawing and data analysis software) is used to obtain the creep fitting equation of bamboo scrimber (Table 3).

Table 3. Initial Strain of Bamboo Scrimber Columns Fitting Equation of Creep of Bamboo Scrimber Columns

\begin{tabular}{|c|c|c|}
\hline Stress Ratio & Fitting Equation & Fitting Degree $\left(\mathrm{R}^{2}\right)$ \\
\hline 0.2 & $\varepsilon_{0}=\varepsilon_{0.2}\left(4.95-4.42 e^{-0.03227 t}\right)$ & 0.97213 \\
\hline 0.4 & $\varepsilon_{0}=\varepsilon_{0.4}\left(4.86-4.17 e^{-0.02943 t}\right)$ & 0.98180 \\
\hline
\end{tabular}

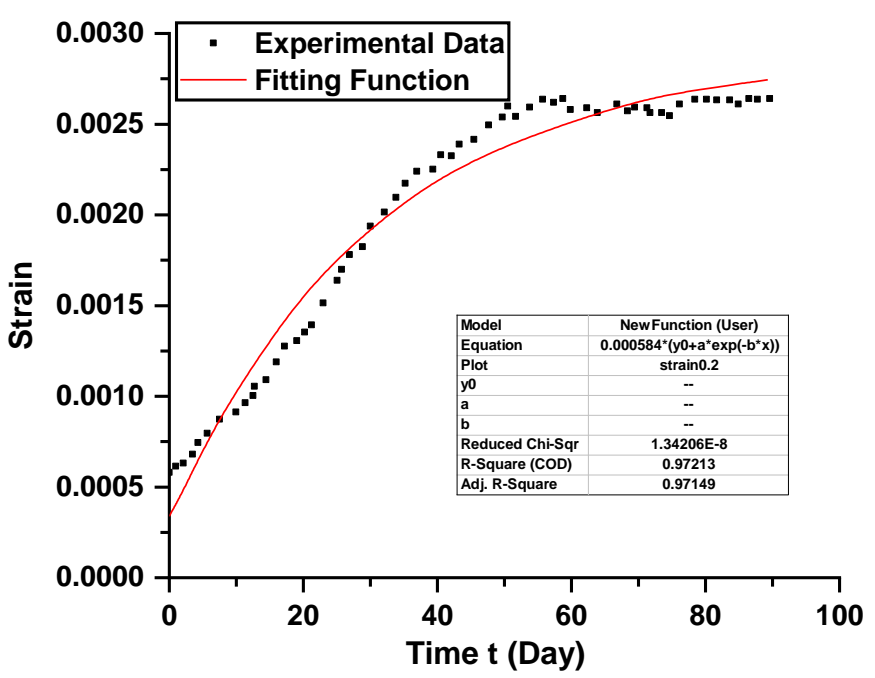

(a)

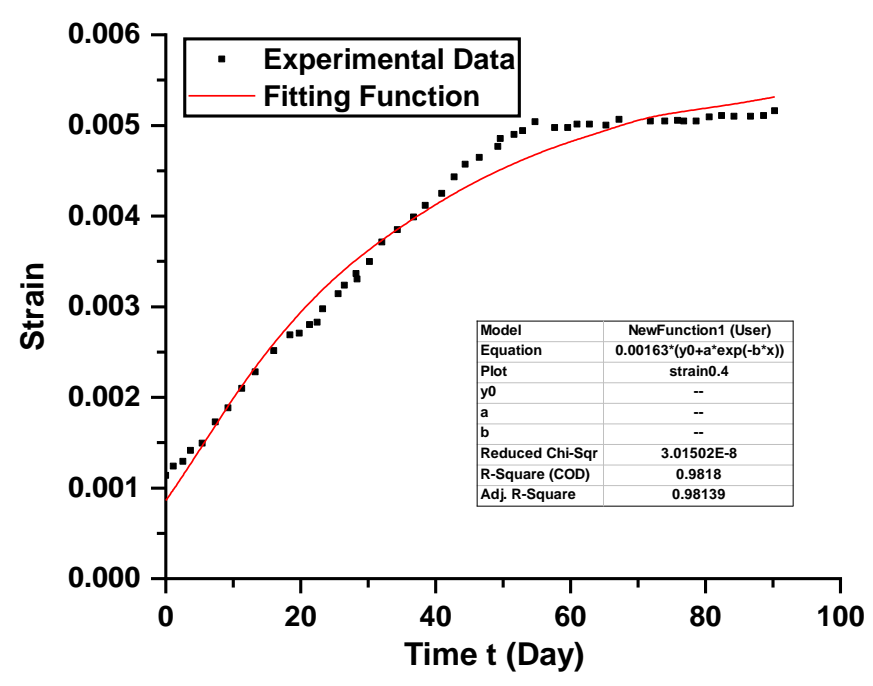

(b)

Fig. 11. Comparison of the three-parameter fitting equation with experimental values: (a) test with stress ratio $=0.2 \times ;(b)$ test with stress ratio $=0.4 \times$

The correspondence between the fitting equation and the values from the creep test experiment was generally good (Fig. 11). This good agreement with the test values means the equation adequately reflects the creep changes that occur in bamboo scrimber columns. The creep load of the specimen with a stress ratio of $0.2 \times$ was $135 \mathrm{kN}$, and that of $0.4 \times$ was $205 \mathrm{kN}$. The $100 \mathrm{kN}$ to $200 \mathrm{kN}$ is the common bearing capacity interval in building construction. Therefore, according to the creep curve and fitted equation, the constitutive creep formula of full-scale bamboo scrimber column is given as follows,

$$
\begin{aligned}
& \varepsilon=\varepsilon_{0}\left(A+B e^{-0.03085 t}\right) \\
& A=-0.45 n+5.04 \\
& B=1.25 n-4.67
\end{aligned}
$$


where $\varepsilon_{0}$ is initial elastic strain, $A$ and $B$ are equation coefficients, $T$ is time (days), and $n$ is the stress ratio. This formula was derived from the test results based on an environment of $20{ }^{\circ} \mathrm{C}$ to $28{ }^{\circ} \mathrm{C}$ (temperature) and $60 \%$ to $85 \%$ (humidity). Further empirical tests are necessary to check the applicability of full-scale bamboo scrimber column in colder and drier areas.

\section{CONCLUSIONS}

From the above research, the following conclusions can be obtained.

1. The stress ratio of long-term load of bamboo scrimber columns should be less than 0.6.

2. From the creep curve of bamboo scrimber column, it can be seen that in the first stage of creep, the creep deformation increased with elapsed time. In the second stage, however, the creep deformation tended to stabilize and the lengthwise dimension reached a stable value; hence, the overall creep curve also conformed to the creep properties of general bamboo material. Under different load levels, the changes of lateral deflection of the two groups of specimens were similar. Humidity had a greater impact on the lateral deflection of the bamboo column, and the deflection value fluctuated. However, the lateral deflection of the whole bamboo scrimber column was very small and mainly involved elastic deformation.

3. The creep deformation of the specimens was basically stable at day 50 and onwards. When the temperature and humidity in the environment changes, the measured data will produce some fluctuation, but the creep value is stable in general. The change of creep under different temperature and humidity conditions indicates that bamboo scrimber is a kind of hygroscopic material that is easily influenced by its local environment.

4. Considering the influence of environmental humidity and temperature, the temperature coefficient and humidity coefficient were substituted into a three-parameter model, and the compression creep constitutive equation of recombined full-scale bamboo column was solved by fitting. When the temperature and humidity change, the process of creep strain and creep deflection are observed from macroscopic point of view. The research on the creep mechanism of recombined bamboo helps to promote the application of bamboo scrimber column in civil engineering.

\section{AKNOWLEDGMENTS}

The authors thank the National Science Foundation of China and Ministry of Science and Technology of China. This research was funded by the National Science Foundation of China in 2019 (Grant No. 51878590) and National Key Research and Development Program in 2017 (Grant No. 2017YFC0703505). 


\section{REFERENCES CITED}

Armstrong, L. D., and Kingston, R. S. T. (1960). "Effect of moisture changes on creep in wood," Nature 185, 862-863. DOI: 10.1038/185862c0

Armstrong, L. D., and Christensen, G. N. (1961). "Influence of moisture changes on deformation of wood under stress," Nature 191, 869-870. DOI: 10.1038/191869a0

ASTM D198 (2015). "Test methods of static tests of lumber in structural sizes," ASTM International, West Conshohocken, PA, USA.

Bazant, Z. P. (1985). "Constitutive equation of wood at variable humidity and tempreture," Wood Science and Techology 19, 159-177. DOI: 10.1007/BF00353077

Bhatnagar, N. S. (1964). "Creep of wood in tension parallel to grain," Holz Als Roh-Und Werkstoff 22(8), 296-299. DOI: 10.1007/BF02608322

Fridley, K. J., Tang, R. C., and Soltis, L. A. (1992). "Creep behavior model for structural lumber," Journal of Structural Engineering 118(8), 2261-2277. DOI:

10.1061/(ASCE)0733-9445(1992)118:8(2261)

GB 50005-2003 (2005). "Code for design of timber structure," Standard of the People's Republic of China, China Architecture and Building Press, Beijing, China. (In Chinese)

Grossman, P. U. A. (1976). "Requirements for a model that exhibits mechano-sorptive behaviour," Wood Science and Technology 10(3), 163-168. DOI:

10.1007/BF00355737

Hu, Y. C. (2008). "The application of rheology in the research of wood composite product," in: The $9^{\text {th }}$ National Conference on rheology of Chinese society of mechanics, Changsha, China. (In Chinese)

Itani, R. Y., Griffith, M. C., and Hoyle, R. J. (1986). "The effect of creep on long wood column design and performance journal of structural engineering," Journal of Structural Engineering 12(5), 1097-1114. DOI:10.1061/(ASCE)07339445(1986)112:5(1097)

Leicester, R. H. (1971). "A rheological model for mechano-sorptive deflections of beams," Wood Science and Techology 5(3), 211-220. DOI: 10.1007/BF00353683

Li, Q., Hua, X. Q., and Qi, L. Z. (2001). "Prospect for re-combined bamboo timber," Journal of Bamboo Research 20(1), 76-80. DOI: 10.3969/j.issn.10006567.2001.01.016 (In Chinese)

Li, N. (2015). A Study on Long-Term Deformation Behavior of Bamboo Components, Master's Thesis, Chongqing Jiaotong University, Chongqing, China. (In Chinese)

Liu, Y., Sheng, X. Q., and Miao, X. C. (2016). "Creep properties of LVL columns of Populus deltoides," Journal of Nanjing University of Technology 38(5), 87-93. DOI: 10.3969/j.issn.1671-7627.2016.05.014 (In Chinese)

Liu, Y., Tang, S. K., Guo, Y. F., Xiao, Z. P., and Su, X. Y. (2020). "Axial compression of three types of bamboo scrimber columns with different cross-sections," BioResources 15(4), 8093-8109. DOI: 10.15376/biores.15.4.8093-8109

Lu, B. X., and Li, J. H. (1989). "Application on viscoelast models in creep of wood," Mechanics in Engineering 11(2), 41-44. DOI: CNKI:SUN:LXYS.0.1989-02-010 (In Chinese)

Lu, B. X., and Li, J. H. (1996). "Creep behavior on a few main species of trees," Mechanics in Engineering 18(1), 36-38. DOI: 10.6052/1000-0992-1996-013 (In Chinese)

Ma, R. Y., and Luo, Y. S. (2008). "Progress and prospect of rheology of wood," in: The $9^{\text {th }}$ National Conference on rheology of Chinese Society of Mechanics, Changsha, China. 
(In Chinese)

Schniewind, A. P. (1967). "Creep-rupture life of Douglas-fir under cyclic environmental conditions," Wood Science and Technology 1(4), 278-288. DOI: 10.1007/BF00349759

Shang, X. X., Ma, Y., and Zhang, J. J. (1998). "Research status and development prospect of reconstituted wood at home and abroad," World Forestry Research 1998(1), 37-42. DOI: CNKI:SUN:SJLY.0.1998-01-006 (In Chinese)

Sheng, X. Q. (2015). Study on the Creep Property of Laminated Veneer Lumber, Master's Thesis, Yangzhou University, Yangzhou, China. (In Chinese)

Shi, J. P., and Wang, P. Y. (1989). "The rheological behaviour of Mongolian oak in compression perpendicular to grain," Wood Industry 3(3), 20-26. DOI: CNKI:SUN:MCGY.0.1989-03-004. (In Chinese)

Wang, P. Y. (1989). "The rheological behaviour of poplar chips in compression perpendicular to grain," Scientia Silvae Scinicae 25(6), 522-528. DOI: CNKI:SUN:LYKE.0.1989-06-004 (In Chinese)

Wang, F. H. (1990). The Effect of Resin pH on the Creep Behavior of Cured Phenol Formaldehyde Resins, Master's Thesis, Northeast Forestry University, Harbin, China.

Wang, S. W. (2007). Experimental Investigations and Numerical Simulation of Creep Behavior of Laminated Veneer Lumber, Master's Thesis, Harbin Institute of Technology, Harbin, China. (In Chinese)

Wu, P. Z. (2015). Test and Analysis of Creep Properties of Bamboo Scrimber, Master's Thesis, Northeast Forestry University, Harbin, China. (In Chinese)

Xiao, Y., Li, L., and Yang, Z. R. (2013). "Experimental investigations on creep and bearing capacity of glued bamboo girder bridge," Building Structure 43(18), 86-91. DOI: CNKI:SUN:JCJG.0.2013-18-021 (In Chinese)

$\mathrm{Xu}, \mathrm{D}$. W., Zhao, Z. P., and Xu, B. (2007). "A study on the transverse rheological properties of bamboo by hot pressing," Bamboo Research Center 26(4), 45-49. DOI: 10.3969/j.issn.1000-6567.2007.04.011 (In Chinese)

Zhou, H. H. (2009). Creep Properties of Laminated Veneer Lumber and Its Effect on Structural Stability, Master's Thesis, Harbin Institute of Technology, Harbin, China. (In Chinese)

Article submitted: September 4, 2020; Peer review completed: November 21, 2020; Revised version received and accepted: March 30, 2021; Published: April 2, 2021. DOI: 10.15376/biores.16.2.3691-3705 